\title{
Rapid Implementation of Service Delivery Changes to Mitigate COVID-19 and Maintain Access to Methadone Among Persons with and at High-Risk for HIV in an Opioid Treatment Program
}

\author{
K. Michelle Peavy ${ }^{1}$ James Darnton ${ }^{1,2} \cdot$ Paul Grekin $^{1,3} \cdot$ Monica Russo' $^{1}$. Caleb J. Banta Green ${ }^{4} \cdot$ Joseph O. Merrill $^{2}$. \\ Charissa Fotinos $^{5}$. Steve Woolworth ${ }^{1} \cdot$ Sean Soth ${ }^{1}$. Judith I. Tsui ${ }^{2}$
}

Published online: 28 April 2020

๑) Springer Science+Business Media, LLC, part of Springer Nature 2020

\begin{abstract}
Medication treatment for opioid use disorder with methadone and buprenorphine is a key HIV prevention strategy [1-5]. Enrollment in medication treatment for opioid use disorder is associated with reductions in injection drug use [6-8], syringe/equipment sharing [6-9], and risky sexual behavior [6, 9]. Among people living with HIV, engagement in medication treatment for opioid use disorder is associated with HIV-risk behavior reductions [10,11], and higher rates of initiating and adhering to antiretroviral treatment (ART) [12-15]. As such, this modality is associated with lower prevalence and incidence rates of HIV itself [16-19]. Many parts of the country, including Seattle, have witnessed outbreaks of HIV among persons who inject drugs related to the opioid crisis [20-23]. Given that medication treatment for opioid use disorder plays a critical role in protecting opioid users from HIV, ensuring continuous medication treatment for opioid use disorder treatment is imperative to help safeguard these individuals from acquiring HIV. Furthermore, this modality of treatment helps those living with HIV to continue to experience its benefits on ART adherence, and promotes HIV control within the surrounding community.

The COVID-19 pandemic represents challenges for continuing opioid treatment services while observing social distancing directives. Here we describe the experience of one
\end{abstract}

\section{K. Michelle Peavy}

peavy@evergreentx.org

1 Evergreen Treatment Services, Seattle, WA, USA

2 Department of Medicine, University of Washington School of Medicine, Seattle, WA, USA

3 Department of Psychiatry and Behavioral Sciences, University of Washington, Seattle, WA, USA

4 Alcohol \& Drug Abuse Institute, University of Washington, Seattle, WA, USA

5 Washington State Health Care Authority, Olympia, WA, USA
Opioid Treatment Program in rapidly creating and implementing policies that balance the safety of patients and staff with uninterrupted access to methadone. We use meeting minutes, personal communications, and written policies to describe: (1) measures adopted at the Opioid Treatment Program to mitigate the spread of COVID-19 while preserving core services to patients; (2) implementation of clinical decision-making strategies aimed at maintaining patient and community safety; and (3) changes in clinic patient flow.

\section{Opioid Treatment Programs}

Opioid Treatment Programs are federally certified and accredited settings in which medications targeting opioid use disorder are provided. They serve individuals with severe opioid use disorder, providing a vital landing place for injection drug users, as well as a conduit for HIV testing and treatment [24]. Treatment provided in Opioid Treatment Programs is different than that of office-based medication treatment as: (1) Opioid Treatment Programs are the only settings in which methadone can be dispensed to treat opioid use disorder; and (2) they have highly regulated dispensaries in which patients come for frequent (i.e., daily for many patients), observed dosing. Longstanding regulations surrounding unsupervised ("take-home") medications are determined on a federal-level [25], and may be subject to further restrictions at the treatment program. The assumption is that daily or frequent supervised dosing enhances safety by reducing risk of medication poisonings and diversion. However, these same policies necessitate large numbers of patients congregating in small spaces for extended periods of time before dispersing to their communities, presenting challenges to infection control. 


\section{Opioid Treatment Program Response to COVID-19}

The country's first SARS-CoV-2 case was confirmed in Washington State, as was the first COVID-19 death. In response, Evergreen Treatment Services-the largest Opioid Treatment Program in Washington State-underwent swift mobilization to develop plans for the impending pandemic. The organization grappled with the dilemma of serving 2630 patients while attempting to minimize physical contact in cramped quarters. Evergreen Treatment Services not only provides medication treatment for opioid use disorder, but also offers an array of critical psychosocial and medical services including HIV screening and referral to treatment. This setting is comprised of three sites, the largest of which $(n=1380$ patients $)$ is located in Seattle, King County, a geographic region in which numerous COVID-19 cases were first identified. This urban site serves among the most vulnerable individuals in the community, with 13 patients known to be living with HIV and up to $63 \%$ reporting homelessness. For many patients, the Opioid Treatment Program is "home base" serving as a consistent setting in which to interface with a medical and counseling professionals, as well as a trusted source for referral to outside services like HIV treatment. Maintaining its core services, this clinic helps people reduce drug use and other HIV risk behaviors, solidifying its role in community HIV prevention.

In February, 2020 Washington State's Governor declared the state's COVID-19 outbreak a public health emergency. Evergreen Treatment Services assembled a trans-disciplinary Infection Control Committee, and initial planning involved preparation around site readiness including personal protective equipment, medication stocks, sanitation, signage/communication, and managing congestion. Policies were clarified and codified around: patient COVID-19 screening, separating symptomatic patients, limiting human contact, messaging around universal precautions/hygienic practices, and defining "essential" staff and services.

At an Opioid Treatment Program, social distancing is made difficult by the reality that most patients engage in almost daily medication dosing. Phase II planning aimed to address this issue by modifying eligibility requirements for take-home doses, increasing the amount of take-homes provided, while balancing the risks of possible medication diversion and drug poisonings (both patients and community members). Opioid Treatment Programs cannot unilaterally relax take-home policies without submitting an exception request to the State Opioid Treatment Authority, housed at the Health Care Authority and SAMHSA's Center for Substance Abuse Treatment. To begin this process, Evergreen Treatment Services proposed take-home status changes for five categories of methadone patients: (1) patients endorsing COVID-19 symptoms (assessed by medical provider) or confirmed disease receive up to 2 weeks of medication; (2) patients who have earned at least one take-home dose (garnered by demonstration of treatment stability using measures including negative urine drug tests and regular medication dosing) receive 1 week's worth of medication; (3) patients over 60 or with medical co-morbidities would be eligible for 1-2 weeks' worth of medication; (4) patients who are deemed unsafe to manage take-homes continue daily dosing; and (5) all other patients who are not in one of the above categories are put on a staggered take-home schedule whereby half the patients present in-person Mondays, Wednesdays, and Fridays, and the other half on opposite days; remaining doses provided as take-homes. These categories were outlined in a comprehensive Infection Control Response document, which was submitted to SAMHSA as a supporting document for the exception. At the same time, the Health Care Authority was working with the Governor's Office and the Washington State Congressional delegation to bring attention to the list of urgent policy exceptions that had been requested to assure programs had the flexibility they needed to safely protect staff and patients. On 3/13/2020, SAMHSA released Evergreen Treatment Services' infection response document as guidance for all Washington State Opioid Treatment Programs [26], after which the exemption was approved and implemented. On 3/16/2020 SAMHSA released adjusted rules governing Opioid Treatment Programs, allowing states to: (1) request blanket exceptions for all stable patients to receive 28-day take-home dosing and; (2) request up to 14-day take-home dosing for less stable patients, but who the Opioid Treatment Program believes can safely handle that level [27].

\section{Clinical Decision Making During COVID-19}

In practice, the most complicated elements of implementing infection control response have been determining which patients are "unstable". Medical providers make determinations around patient stability on a case-by-case basis, some of which are clearly articulated within the documentation parameters, such as an inability to safely take safely medication daily due to a cognitive or psychiatric condition, or inability to keep medication safe due to a chaotic living situation. Yet numerous cases required lengthy and ongoing consultation among medical providers and clinical leadership. For example, individuals living with HIV are some of the most medically complicated patients at the Opioid Treatment Program. Maintaining this group in opioid 
treatment services is critical not only in terms of lowering the likelihood of injection drug use, but also to maintain the connection these patients have to clinic medical and other treatment staff, who can encourage adherence to ART or link these individuals to HIV treatment and services. Decisions on take-home dosing for patients with HIV were reviewed on a case-by-case basis that balanced patients' vulnerability to COVID-19 with risks posed by providing potentially unstable patients with large doses of methadone. These discussions revolved around key risk factors, heavily emphasizing drug poisoning risks (e.g., recent drug poisoning events; documented drug impairment incidents). During the COVID-19 outbreak, standard tools for safety monitoring are suspended, namely drug testing is considered "nonessential", and breathalyzing is an aerosolizing activity that increases the risk of contagion. The guiding principle for decision making is safety of the patients and public, both in terms of infectious disease risk, as well as from a medication diversion standpoint. We continue to explore medication diversion prevention; at the time of this writing, the clinic is implementing a pilot of a smartphone app which will allow video-directly observed therapy [28].

\section{Impact on Opioid Treatment Program Service Delivery}

While the impact of the COVID-19 on Opioid Treatment Programs and their patients cannot yet be fully appreciated, we describe initial patient flow variables before and after the onset of the pandemic. Two time periods spanning Monday-Saturday (excluding Sunday due to clinic closure) were compared: (1) "Before COVID-19"; February 24-29; and (2) "After COVID-19", March 30-April 4. The percentage of on-site visits given that day's census was calculated for each day of the time period. Before COVID-19, an average of $61.9 \%$ of patients were on site for dosing; this dropped to $31.1 \%$, representing a $49.2 \%$ decrease. Of note, the Opioid Treatment Program maintained the same level of admissions (i.e. new patients initiating treatment) as pre-COVID-19.

Our initial effort encapsulates lessons learned from one Opioid Treatment Program when rapid implementation of new policies takes place in the face of extenuating circumstances. Namely, despite decades of mandates requiring supervised methadone dosing visits, policies were rapidly changed during a national crisis in order to ensure uninterrupted access to methadone while balancing efforts to mitigate COVID-19 risk. Our experience highlights that organization-level decisions can be made quickly, resulting in both the reduction in the number of persons on site by almost half, as well as a slight increase in the overall census. An unexpected bright spot of COVID-19 is the opportunity to formally evaluate a set of forcibly changed standard practices that have been called out for reform [29]. The effects of providing extended take-homes is unknown, and future research will be needed to study the effects of these changes on methadone-implicated poisonings, mortality, treatment retention, and HIV-risk behaviors and outcomes. As the pandemic evolves, we may find more people in need of opioid treatment due to reductions in drug supply, economic downturn, or other unpredictable eventualities. Increases in Opioid Treatment Program censuses, as was the case for Evergreen Treatment Services in the past month, will also bring more opportunities for these programs to provide HIV screening, testing, and linkage to treatment, a vital role that this setting can serve for opioid users.

\section{References}

1. Ball JC, Lange WR, Myers CP, Friedman SR. Reducing the risk of AIDS through methadone maintenance treatment. J Health Soc Behav. 1988;2(3):214-26.

2. Karki P, Shrestha R, Huedo-Medina TB, Copenhaver M. The impact of methadone maintenance treatment on HIV risk behaviors among high-risk injection drug users: a systematic review. Evid Based Med Public Health. 2016;2:e1229.

3. Metzger DS, Woody GE, O'Brien CP. Drug treatment as HIV prevention: a research update. J Acquir Immune Defic Syndr. 2010;55(Suppl 1):S32.

4. Sorensen JL, Copeland AL. Drug abuse treatment as an HIV prevention strategy: a review. Drug Alcohol Depend. 2000;59(1):17-311.

5. Gowing L, Farrell M, Bornemann R, Sullivan LE, Ali R. Substitution treatment of injecting opioid users for prevention of HIV infection. Cochrane Database Syst Rev. 2008. https://doi. org/10.1002/14651858.CD004145.pub3.

6. Corsi KF, Lehman WK, Booth RE. The effect of methadone maintenance on positive outcomes for opiate injection drug users. J Subst Abuse Treat. 2009;37(2):120-6.

7. Millson P, Challacombe L, Villeneuve PJ, Strike CJ, Fischer B, Myers T, Shore R, Hopkins S. Reduction in injection-related HIV risk after 6 months in a low-threshold methadone treatment program. AIDS Educ Prev. 2007;19(2):124-36.

8. Chen W, Xia Y, Hong Y, Hall BJ, Ling L. Predictors of continued HIV-risk behaviors among drug users in methadone maintenance therapy program in China- a prospective study. Harm Reduct J. 2013;10(1):23.

9. Wang M, Mao W, Zhang L, Jiang B, Xiao Y, Jia Y, Wu P, Cassell $\mathrm{H}$, Vermund S. Methadone maintenance therapy and HIV counseling and testing are associated with lower frequency of risky behaviors among injection drug users in China. Subst Use Misuse. 2015;50(1):15-23.

10. Pettes T, Wood E, Guillemi S, Lai C, Montaner J, Kerr T. Methadone use among HIV-positive injection drug users in a Canadian setting. J Subst Abuse Treat. 2010;39(2):174-9.

11. Woody G, Bruce D, Korthuis PT, Chhatre S, Hillhouse M, Jacobs P, Sorensen J, Saxon AJ, Metzger D, Ling W. HIV risk reduction with buprenorphine-naloxone or methadone: findings from a randomized trial. J Acquir Immune Defic Syndr. 2014;66(3):288.

12. Uhlmann S, Milloy MJ, Kerr T, Zhang R, Guillemi S, Marsh D, Hogg RS, Montaner JS, Wood E. Methadone maintenance therapy promotes initiation of antiretroviral therapy among injection drug users. Addiction. 2010;105(5):907-13. 
13. Roux P, Carrieri MP, Cohen J, Ravaux I, Poizot-Martin I, Dellamonica P, Spire B. Retention in opioid substitution treatment: a major predictor of long-term virological success for HIV-infected injection drug users receiving antiretroviral treatment. Clin Infect Dis. 2009;49(9):1433-40.

14. Lappalainen L, Nolan S, Dobrer S, et al. Dose-response relationship between methadone dose and adherence to antiretroviral therapy among HIV-positive people who use illicit opioids. Addiction. 2015;110(8):1330-9. https://doi.org/10.1111/add.12970.

15. Altice FL, Bruce RD, Lucas GM, et al. HIV treatment outcomes among HIV-infected, opioid-dependent patients receiving buprenorphine/naloxone treatment within HIV clinical care settings: results from a multisite study. J Acquir Immune Defic Syndr. 2011;56(Suppl 1):S22-S32. https://doi.org/10.1097/ QAI.0b013e318209751e.

16. MacArthur GJ, Minozzi S, Martin N, Vickerman P, Deren S, Bruneau J, Degenhardt L, Hickman M. Opiate substitution treatment and HIV transmission in people who inject drugs: systematic review and meta-analysis. BMJ. 2012;345:e5945.

17. Metzger DS, Woody GE, McLellan AT, O'Brien CP, Druley P, Navaline H, DePhilippis D, Stolley P, Abrutyn E. Human immunodeficiency virus seroconversion among intravenous drug users in-and out-of-treatment: an 18-month prospective follow-up. J Acquir Immune Defic Syndr. 1993;6:1049.

18. Novick DM, Joseph H, Croxson TS, Salsitz EA, Wang G, Richman BL, Poretsky L, Keefe JB, Whimbey E. Absence of antibody to human immunodeficiency virus in long-term, socially rehabilitated methadone maintenance patients. Arch Intern Med. 1990;150(1):97-9.

19. Serpelloni G, Carrieri MP, Rezza G, Morganti S, Gomma M, Binkin N. Methadone treatment as a determinant of HIV risk reduction among injecting drug users: a nested case-control study. AIDS Care. 1994;6(2):215-20.

20. Golden MR, Lechtenberg R, Glick SN, et al. Outbreak of human immunodeficiency virus infection among heterosexual persons who are living homeless and inject drugs - Seattle, Washington, 2018. MMWR Morb Mortal Wkly Rep. 2019;68:344-9. https:// doi.org/10.15585/mmwr.mm6815a2.

21. Peters PJ, Pontones P, Hoover KW, Patel MR, Galang RR, Shields J, Blosser SJ, Spiller MW, Combs B, Switzer WM, Conrad C, Gentry J, Khudyakov Y, Waterhouse D, Owen SM, Chapman E, Roseberry JC, McCants V, Weidle PJ, Broz D, Samandari T,
Mermin J, Walthall J, Brooks JT, Duwve JM. HIV infection linked to injection use of oxymorphone in Indiana, 2014-2015. N Engl J Med. 2016;375(3):229-39. https://doi.org/10.1056/NEJMoa1515 195.

22. Cranston K, Alpren C, John B, et al. Notes from the field: HIV diagnoses among persons who inject drugs-Northeastern Massachusetts, 2015-2018. MMWR Morb Mortal Wkly Rep. 2019;68:253-4. https://doi.org/10.15585/mmwr.mm6810a6.

23. Evans ME, Labuda SM, Hogan V, et al. Notes from the field: HIV infection investigation in a rural area-West Virginia, 2017. MMWR Morb Mortal Wkly Rep. 2018;67:257-8. https://doi. org/10.15585/mmwr.mm67086.

24. Spire B, Lucas GM, Carrieri MP. Adherence to HIV treatment among IDUs and the role of opioid substitution treatment (OST). Int J Drug Pol. 2007;18(4):262-70.

25. Office of the Federal Register (OFR) and the Government Publishing Office. Electronic Code of Federal Regulations. Updated April 8th, 2020. https://www.ecfr.gov/cgi-bin/retrieveEC FR?gp=3\&SID=7282616ac574225f795d5849935efc $45 \&$ ty $=H$ TML\&h=L\&n=pt42.1.8\&r=PART. Accessed 9 Apr 2020.

26. Washington State Health Care Authority (HCA). COVID-19 and opioid treatment programs Frequently Asked Questions. https:// www.hca.wa.gov/assets/program/opioid-treatment-program-faq. pdf. Accessed 13 Mar 2020

27. Substance Abuse and Mental Health Services Administration (SAMHSA). Opioid Treatment Program Guidance. https:// www.samhsa.gov/sites/default/files/otp-guidance-20200316.pdf. Accessed 19 Mar 2020

28. Godersky ME, Klein JW, Merrill JO, Blalock KL, Saxon AJ, Samet JH, Tsui JI. Acceptability and feasibility of a mobile health application for video directly observed therapy of buprenorphine for opioid use disorders in an office-based setting. J Addict Med. 2020. https://doi.org/10.1097/adm.0000000000000608.

29. Samet JH, Botticelli M, Bharel M. Methadone in primary careone small step for Congress, one giant leap for addiction treatment. N Engl J Med. 2018;379(1):7-8.

Publisher's Note Springer Nature remains neutral with regard to jurisdictional claims in published maps and institutional affiliations. 